\title{
Effects of upper airway anaesthesia on respiratory-related evoked potentials in
} humans

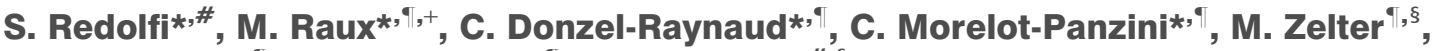 \\ J-P. Derenne*, ${ }^{\star,}$ T. Similowski*, and C. Straus ${ }^{\#, \$}$
}

ABSTRACT: Cortical potentials evoked by mid-inspiratory occlusion arise from numerous receptors, many of which are probably within the upper airway. Their precise nature is not known. The aim of the current study was to improve knowledge of this by studying the effects of topical upper airway anaesthesia on respiratory-related evoked potentials.

Respiratory-related evoked potentials were described through the averaging of electroencephalogram (EEG) epochs following mid-inspiratory occlusions ( $C_{3}-C_{2} ; C_{4}-C z$ ). A total of 21 healthy volunteers (13 male, aged 22-52 yrs) were studied during mouth breathing, before and after topical upper airway anaesthesia (lidocaine). Moreover, 15 subjects were studied during nose breathing with and without anaesthesia. Six subjects were studied whilst inhaling L-menthol.

Typical potentials were present in all the subjects, their components featuring normal amplitudes and latencies. The route of breathing and upper airway anaesthesia did not modify the EEG responses to inspiratory occlusions, qualitatively or quantitatively, during mouth or nose breathing. L-menthol had no effect.

Upper airway receptors sensitive to topical anaesthesia are unlikely to contribute significantly to mid-inspiratory occlusion-evoked potentials. On the contrary, deeper receptors, such as joint and muscle receptors, could contribute dominantly to these potentials.

KEYWORDS: Dyspnoea, L-menthol inhalation, respiratory-related evoked potentials, upper airway, upper airway anaesthesia

V arious respiratory stimuli can evoke cortical potentials in humans. These include direct stimulation of intercostal muscles [1] or phrenic nerve stimulation [2, 3]. Sudden pressure changes within the airway appear particularly apt at evoking cortical responses. These can be induced by: 1) occlusion of the airway at the mouth at the beginning of inspiration [4] or during it [5]; 2) occlusion of the airway at the mouth during expiration [6]; 3) the sudden application of inspiratory resistances [7]; and 4) the application of negative pressure pulses to the airways during inspiration [8] or expiration [9].

The study of the cortical activity in response to respiratory events is a powerful means to improve the physiological knowledge of the relationship between the respiratory system and the brain. By extension, this type of research could lead to a better understanding of the mechanisms underlying certain respiratory sensations through the establishment of the corresponding neurophysiological substrates. Examples of such perspectives are given in the study by KNAFELC et al. [10] relating some characteristics of respiratory-related evoked potentials to the magnitude estimation of mechanical loads, or in the study by DAVENPORT et al. [11] identifying, in asthmatic children, an association between the lack of the early component of the respiratory-related evoked potentials and a past history of life-threatening asthma. Within this frame, understanding the very determinants of respiratory-related evoked potentials is an important prerequisite.

Although the cortical responses to pressure changes applied at the airway opening can reflect the activation of afferent pathways from various components of the respiratory system, several lines of evidence point to the upper airway as one of their major determinants. Indeed, DAUBENSPECK et al. [12], studying the potentials evoked by brief negative pressure pulses in terms of global field power, described major alterations in both the early and late cortical activity when the stimuli

\section{AFFILIATIONS}

*Laboratoire de Physiopathologie Respiratoire, Service de Pneumologie,

${ }^{+}$Dept of Anesthesia and Intensive Care,

${ }^{\S}$ Service Central d'Explorations Fonctionnelles Respiratoires, Groupe Hospitalier Pitié-Salpêtrière,

Assistance Publique, Hôpitaux de Paris, and

-UPRES EA 2397, Université Pierre et Marie Curie Paris VI, Paris, France.

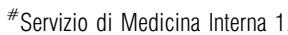
Spedali Civili, and Universita di Brescia, Brescia, Italy.

CORRESPONDENCE

T. Similowski

Laboratoire de Physiopathologie Respiratoire

Service de Pneumologie et de Réanimation

Groupe Hospitalier Pitié-Salpêtriêre 47-83

Bd de l'Hôpital

75651 Paris Cedex 13

France

Fax: 33142176708

E-mail: thomas.similowski@psl.

ap-hop-paris.fr

Received:

December 082004

Accepted after revision:

August 082005

\section{SUPPORT STATEMENT}

This study was supported by Contrat de recherche triennal "Legs Poix" de la Chancellerie des Universités de Paris and Association pour le

Développement et l'Organisation de la Recherche en Pneumologie (ADOREP), Paris, France. S. Redolfi was a scholar of Universita di Brescia, Brescia, Italy.

European Respiratory Journal Print ISSN 0903-1936 Online ISSN 1399-3003 
were applied through a laryngeal mask (that bypasses most of the upper airway but not laryngeal afferents). In tracheotomised patients suffering from inspiratory muscle pump dysfunction, DONZEL-RAYNAUD et al. [13] showed that applying mid-inspiratory occlusions to the trachea suppressed responses that were consistently present when occlusions were applied to the mouth.

The upper airway contains several types of receptors, including irritant receptors, and flow, pressure and "drive" receptors $[14,15]$, sensing changes in the prevailing status of the respiratory system. The location of these receptors range from mucosal or submucosal (e.g. the cold receptors activated by changes in flow, or laryngeal irritant receptors) to intramuscular and articular (e.g. the spindles and tendon organs of the numerous upper airway muscles, or joint receptors). Whether the cortical responses to airway pressure changes involve the stimulation of an array of these receptors or of one category preferentially is unknown. The present study was designed in an attempt to provide some answers to this question. Its aim was to take advantage of the different sensitivities of upper airway receptors to topical anaesthesia [14, 15] to better understand their respective contributions to the cortical responses following mid-inspiratory occlusions.

\section{MATERIAL AND METHODS \\ Subjects and study conditions}

A total of 21 healthy volunteers (13 male, eight female, aged $22-52 \mathrm{yrs}$, body mass index $19-30 \mathrm{~kg} \cdot \mathrm{m}^{-2}$ ) participated in the study after completion of the French legal procedure for human biomedical research. They received detailed information on the study and gave written consent.

The subjects were studied semi-reclined in a comfortable lounge chair with their back, neck and head comfortably supported. They were instructed to relax but to keep their eyes open in order to avoid any risk of falling asleep or producing slow brain waves. They wore earplugs and headphones through which they listened to a quiet musical piece of their choice, in order to mask auditory cues. The breathing circuit was firmly held by a metallic frame at the level of their mouth, in order to minimise artefacts due to the activity of facial muscles.

\section{Measurements and procedures}

\section{Breathing apparatus}

During the experiments involving mouth breathing (see later) the subjects, wearing a nose clip, breathed room air through a flanged mouthpiece attached to a heated pneumotachometer (Hans-Rudolf 3700; Hans-Rudolf, Kansas City, MO, USA) combined with a $\pm 2 \mathrm{cmH}_{2} \mathrm{O}$ linear differential pressure transducer (Validyne, Northridge, CA, USA) to measure ventilatory flow, and connected to a nonrebreathing valve (Hans-Rudolf 2600; Hans-Rudolf) of which the inspiratory port could be occluded by an inflatable balloon (Hans-Rudolf 9340 occlusion valve and 9330 compressor; Hans-Rudolf). Mouth pressure $(\mathrm{Pm})$ was measured from a side port of the mouthpiece (DP 15-32 transducer, $\pm 50 \mathrm{cmH}_{2} \mathrm{O}$; Validyne, Northridge, CA, USA). Of note, the inspiratory limb of the circuit was also equipped with a small reservoir in which it was possible to deposit L-menthol crystals (see later). During the experiments involving nose breathing (see later), the same apparatus was used, but the subjects breathed through an airtight nasal mask (Comfort Classic; Respironics, Nantes, France) to which the pneumotachometer was connected and within which mask pressure (Pmask) could be measured. Subjects were instructed to keep their mouth tightly closed.

\section{Respiratory-related evoked potentials}

Surface electrodes were placed over the somatosensory region of the cerebral cortex at $\mathrm{Cz}, \mathrm{C} 3, \mathrm{C} 4$ on the basis of the international 10-20 system. $\mathrm{C}_{3}$ and $\mathrm{C} 4$ were referenced to $\mathrm{CZ}$ to record the left and right activity, respectively. Electrode impedances were maintained below $5 \mathrm{k} \Omega$. Respiratory-related potentials were evoked by $400-500 \mathrm{~ms}$ mid-inspiratory occlusions [5], randomly presented every three to six breaths (midinspiratory occlusions were chosen, as in previous studies by the present authors [13, 16], because they give potentials "sharper" than those elicited by onset-inspiratory occlusions [5]). The signals were sampled at $1 \mathrm{kHz}$ over a $0.5 \mathrm{~Hz}-500 \mathrm{~Hz}$ bandwidth (Neuropack Sigma®; Nihon Kohden, Tokyo, Japan), digitised $100 \mathrm{~ms}$ before and $2 \mathrm{~s}$ after the inspiratory onset determined from the flow trace, and stored on an Apple Macintosh computer for subsequent analysis (PowerLab ${ }_{\mathbb{B}}$; AD instruments, Hastings, UK). Data analysis was performed offline. The individual presentations for a given trial were recalled from computer memory and displayed on screen. The occluded inspirations were then selected using the $P \mathrm{~m}$ signal. A given occluded breath was retained for averaging only in the presence of a stable electroencephalogram (EEG) signal baseline and in the absence of obviously aberrant accidents. In addition, "control" trials were obtained by averaging the same number of unoccluded breaths. To ensure the immediate reproducibility of the signals, two separate averagings of 80 occluded breaths were systematically performed in each of the study conditions and the resulting traces superimposed. Ensemble averaging of all the traces was then performed.

The peak latencies of the first positive (P1), first negative (N1), second positive (P2) and second negative (N2) components of the respiratory-related evoked potentials were measured according to DAVENPORT et al. [17], from a "zero" point determined on the averaged $P \mathrm{~m}$ trace as the point of intersection of a line drawn through the $P$ m baseline with a second line drawn through the steepest portion of the $P \mathrm{~m}$ swing (MatLab5.3 ${ }_{\circledR}$; The Math Works, Natick, MA, USA). The amplitude of all the components was measured from baseline to peak.

\section{Upper airway anaesthesia}

A 5\% lidocaine hydrochloride solution was sprayed in the nasal and buccal cavities until they were anaesthetised to touch. Subjects were asked to swallow the anaesthetic in order to achieve anaesthesia of the posterior pharynx. If necessary, additional xylocaine was administered up to the suppression of the gag reflex and then further sprayed as distally as possible from the posterior oropharynx. The total lidocaine dose necessary to achieve this result never exceeded $400 \mathrm{mg}$. All the subjects reported swallowing difficulties at the end of the procedure. Local sensitivity was tested during the interval between the two experimental runs performed under topical 
anaesthesia (see later). To do this, the subjects were asked whether their bucco-pharyngeal sensations had changed and if the swallowing difficulties initially reported persisted. In addition, the posterior part of the pharynx was probed with a spatula and the subjects were asked if they felt the touch or felt nausea. If the answer was "yes" to any of these questions, additional lidocaine was administered.

\section{Experimental design}

Each experimental session consisted of a baseline evaluation made up of two separate series of inspiratory occlusions, followed by a "test" evaluation also made up of two separate series of inspiratory occlusions. Three sets of experiments were conducted, listed as follows. 1) Effects of upper airway anaesthesia on the cortical potentials evoked by inspiratory occlusions performed during mouth breathing. All 21 subjects participated in the current study. In six cases, additional recordings were made after a 90-min washout following anaesthesia. 2) Effects of upper airway anaesthesia on the cortical potentials evoked by inspiratory occlusions performed during nose breathing. A subset of 15 subjects participated in the present study, which was conducted on a separate day. 3) Effects of cold receptor stimulation on the cortical potentials evoked by inspiratory occlusions performed during mouth breathing. In six subjects, the inhalation of L-menthol $(300 \mathrm{mg}$ of L-menthol crystals deposited in the reservoir connected to the inspiratory limb of the breathing circuit) was used to stimulate upper airway flow receptors. A specific experimental session was performed according to the same design and procedures on a separate day. The effect of L-menthol was considered complete $5 \mathrm{~min}$ after the beginning of inhalation [18].

In addition, the effects of upper airway anaesthesia on the sensations associated with the inhalation of L-menthol were evaluated during mouth breathing in 18 subjects and during nose breathing in 15 subjects.

\section{Statistical analysis}

Data are presented as mean $\pm \mathrm{SD}$. After checking for the normality and homoscedasticity of the data sets, the right-toleft comparison of the latencies and amplitudes of the potentials was conducted using a paired t-test, as were the comparisons between the results obtained with the oral and nasal routes of breathing and between the baseline and test conditions. In the six subjects in whom washout measurements were made, the three conditions were compared with a linear ANOVA with the Tukey post hoc test. Differences were considered significant when the probability of a type I error was $<5 \%$.

\section{RESULTS}

Typical respiratory-related evoked potentials (figs 1-3) were present bilaterally in all the subjects at baseline.

Under baseline conditions, the average latencies and amplitude of the components were within the normal range (Before columns in tables 1 and 2). There was no significant right-toleft difference. The latencies and amplitudes measured during mouth and nose breathing were also not significantly different from one another (fig. 1).
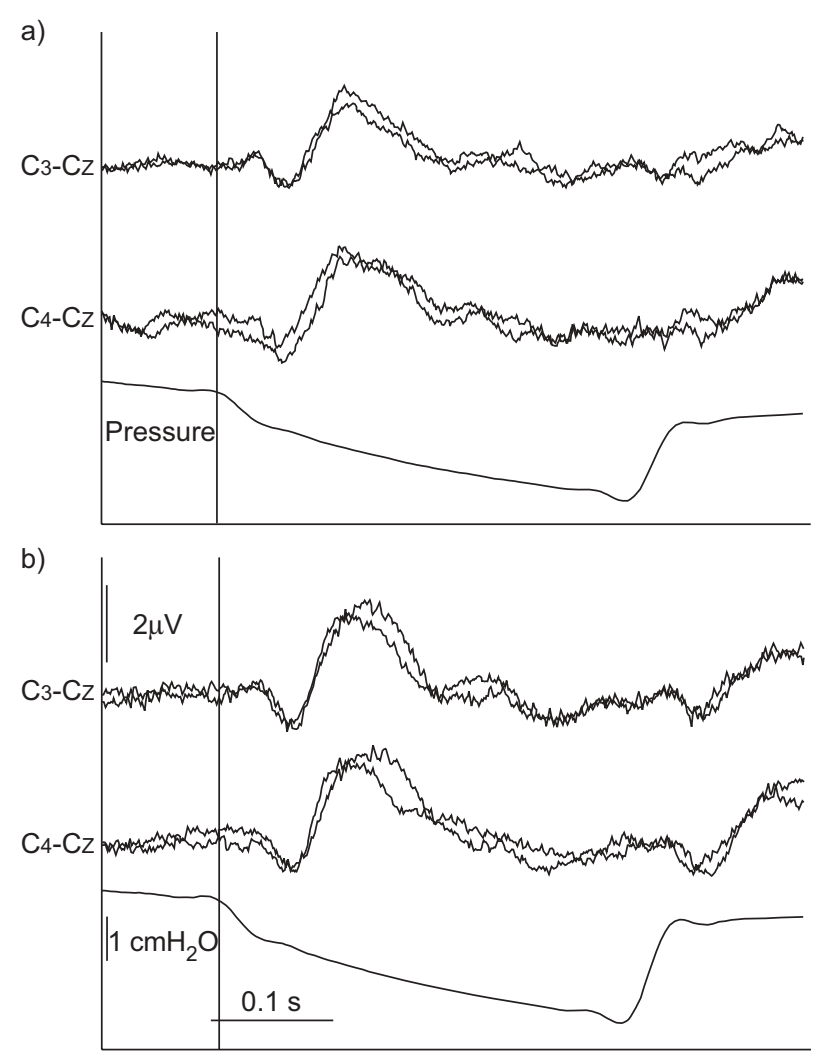

FIGURE 1. Respiratory-related evoked potentials elicited by mid-inspiratory occlusions applied during a) mouth breathing and b) nose breathing in 15 subjects in whom both breathing routes were compared. $\mathrm{C}_{3}-\mathrm{C} z$ and $\mathrm{C}_{4}-\mathrm{Cz}$ corresponds to the ensemble averaging of the inspiratory occlusion-related electroencephalogram epochs obtained in all the subjects. In each of the $\mathrm{C}_{3}-\mathrm{Cz}$ and $\mathrm{C}_{4}-\mathrm{Cz}$ derivation in a) and $b$ ), one of the two traces corresponds to the potentials recorded at baseline and the other one to the potentials recorded after upper airway anaesthesia (no significant difference). The potentials recorded during nose breathing appear slightly sharper than those recorded during mouth breathing, but the latencies and amplitudes were not significantly different. The vertical line indicates the zero point (see Materials and methods)

Upper airway anaesthesia (21 subjects) did not decrease the number of occurrences of the respiratory-related evoked potentials and of their successive components. It did not affect the latencies of the components and did not influence their amplitudes (figs 1 and 2; tables 1 and 2). This was true on either side and during both mouth and nose breathing. In the six subjects so tested, the washout data were not different from the baseline and anaesthesia data (fig. 2).

Similarly, the inhalation of L-menthol (six subjects) did not decrease the number of occurrences of the respiratory-related evoked potentials and of their successive components. It did not affect the latencies of the components nor did it influence their amplitudes (fig. 3; tables 3 and 4). In the six subjects tested, the washout data were not different from the baseline and anaesthesia data (fig. 3).

Upper airway anaesthesia consistently abolished the cold-like sensation associated with the inhalation of L-menthol during both nose breathing and mouth breathing. 


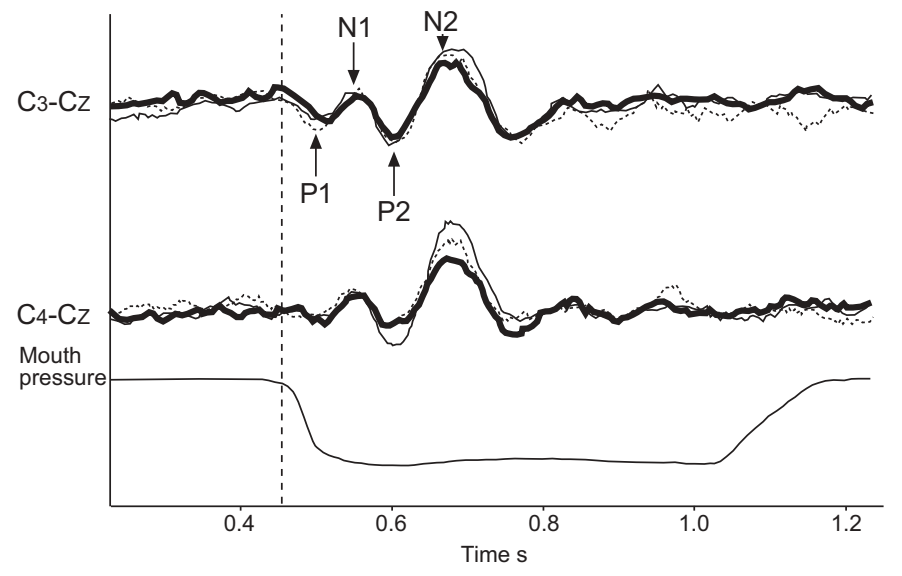

FIGURE 2. An example of the respiratory-related evoked potentials observed before (-), during ( $(-)$ and after ( $\cdots \cdot)$ upper airway anaesthesia in one subject. Each trace in $\mathrm{C}_{3}-\mathrm{Cz}$ and $\mathrm{C}_{4}-\mathrm{Cz}$ corresponds to the ensemble averaging of two separate superimposable traces obtained from 80 mid-inspiratory occlusions. The vertical line indicates the zero point (see Materials and methods). Typically, the potentials begin with a first positive component (P1; 40-60 ms after the beginning of the load-related change in mouth pressure), considered to reflect the cortical arrival of the afferent message. Later components, typically negative, positive and negative again (N1, P2, and N2, respectively) may reflect the cognitive processing of the sensory information to various extents, as would further components occurring $\sim 300 \mathrm{~ms}$ after the stimulus.

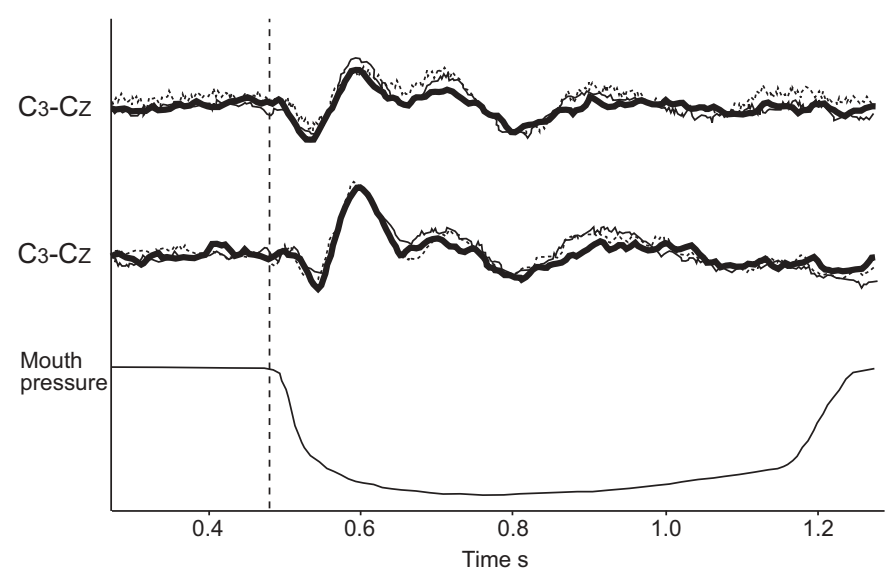

FIGURE 3. An example of the respiratory-related evoked potentials before (-), during $(-)$ and after $(\cdots)$ inhalation of $\mathrm{L}-$ menthol in one subject. Each trace in $\mathrm{C}_{3}-\mathrm{CZ}$ and $\mathrm{C}_{4}-\mathrm{Cz}$ corresponds to the ensemble averaging of two separate superimposable traces obtained from 80 mid-inspiratory occlusions. The vertical line indicates the zero point (see Materials and methods).

\section{DISCUSSION}

The present study shows that upper airway anaesthesia does not affect the cortical potentials evoked by mid-inspiratory occlusions in normal humans. This observation can be used to reason about the source of the respiratory-related evoked potentials, keeping in mind that the corresponding hypothesis may not extend to other categories of individuals.

\section{Preliminary considerations}

First of all, it must be acknowledged that the absence of effects of upper airway anaesthesia on the respiratory-related evoked

\begin{tabular}{|c|c|c|c|c|}
\hline \multirow[t]{3}{*}{ TAE } & $\begin{array}{l}\text { Late } \\
\text { relat } \\
\text { upp } \\
\text { durir }\end{array}$ & \multicolumn{3}{|c|}{$\begin{array}{l}\text { Latencies of the components of the respiratory- } \\
\text { related evoked potentials before and during } \\
\text { upper airway anaesthesia in } \mathrm{Cz}-\mathrm{C}_{3} \text { and } \mathrm{Cz}-\mathrm{C}_{4} \\
\text { during mouth breathing }\end{array}$} \\
\hline & \multicolumn{2}{|c|}{$\mathrm{Cz}-\mathrm{C}_{3}$} & \multicolumn{2}{|c|}{$\mathrm{Cz}-\mathrm{C}_{4}$} \\
\hline & Before $^{\#}$ & During $^{\#}$ & Before $^{\#}$ & During\# \\
\hline P1 & $\begin{array}{c}50.56 \pm 14.19 \\
\text { (18) }\end{array}$ & $\begin{array}{c}55.82 \pm 17.58 \\
(19)\end{array}$ & $\begin{array}{c}51.42 \pm 16.02 \\
(20)\end{array}$ & $\begin{array}{c}55.04 \pm 14.27 \\
(18)\end{array}$ \\
\hline N1 & $\begin{array}{c}108.5 \pm 17.91 \\
(20)\end{array}$ & $\begin{array}{c}111.9 \pm 20.52 \\
(19)\end{array}$ & $\begin{array}{c}113.1 \pm 21.16 \\
(20)\end{array}$ & $\begin{array}{c}121.00 \pm 21.82 \\
(19)\end{array}$ \\
\hline P2 & $\begin{array}{c}175 \pm 22.49 \\
(19)\end{array}$ & $\begin{array}{c}172.7 \pm 32.23 \\
(17)\end{array}$ & $\begin{array}{c}188.5 \pm 37.27 \\
(15)\end{array}$ & $\begin{array}{c}193.7 \pm 37.75 \\
(17)\end{array}$ \\
\hline N2 & $\begin{array}{c}234.4 \pm 25.57 \\
(17)\end{array}$ & $\begin{array}{c}233.4 \pm 28.93 \\
(15)\end{array}$ & $\begin{array}{c}245.5 \pm 35.32 \\
(12)\end{array}$ & $\begin{array}{c}246.8 \pm 46.74 \\
(14)\end{array}$ \\
\hline
\end{tabular}

Data are presented as mean \pm SD of the measured latency in ms (number of occurrences of the component). P1, N1, P2, N2: peak latencies of the first positive, first negative, second positive and second negative components of the respiratory-related evoked potentials, respectively. ${ }^{\#}: n=21$.

TABLE 2 Amplitudes of the components of the respiratory-
related evoked potentials (measured from
baseline to peak) before and during upper airway
anaesthesia in Cz-C3 and Cz-C4 during mouth
breathing

Data are presented as mean \pm SD of the measured amplitudes in $\mu \mathrm{V}$ (number of occurrences of the component). P1, N1, P2, N2: peak latencies of the first positive, first negative, second positive and second negative components of the respiratory-related evoked potentials, respectively. ${ }^{\#}: \mathrm{n}=21$.

potentials could mean that the contribution of the upper airway to the respiratory-related evoked potentials is unimportant, or, alternatively, fully redundant. In patients with various types of inspiratory muscle pump dysfunction, DONZEL-RAYNAUD et al. [13] have shown that the upper airways are crucial for the early components of the respiratory-related evoked potentials to occur. However, comparable information is currently lacking in healthy subjects, and it is thus not completely possible to exclude that the observations made by DONZEL-RAYNAUD et al. [13], which were conditioned by the absence or abnormality of afferent traffic from the rib cage and ventilatory muscles in the patients studied. In healthy subjects or in other diseases, the mechanisms of regulation can be different. Notably, however, DAUBENSPECK et al. [12] observed an important fall in the global field power evoked by upper 


\begin{tabular}{|c|c|c|c|c|c|c|}
\hline \multirow[t]{3}{*}{ TA } & \multicolumn{6}{|c|}{$\begin{array}{l}\text { Latencies of the components of the respiratory-related evoked potentials before, during and after inhalation of L- } \\
\text { menthol, in } \mathrm{Cz}-\mathrm{C}_{3} \text { and } \mathrm{Cz}-\mathrm{C}_{4}\end{array}$} \\
\hline & \multicolumn{3}{|c|}{$\mathrm{Cz}_{-} \mathrm{C}_{3}$} & \multicolumn{3}{|c|}{$\mathrm{Cz}_{-}-\mathrm{C}_{4}$} \\
\hline & Before & During & After & Before & During & After \\
\hline P1 & $38.00 \pm 8.00$ & $39.60 \pm 3.21$ & $39.00 \pm 4.47$ & $40.20 \pm 8.14$ & $38.20 \pm 10.71$ & $41.80 \pm 13.44$ \\
\hline P2 & $148.00 \pm 9.57$ & $163.80 \pm 22.92$ & $163.60 \pm 20.11$ & $148.25 \pm 15.90$ & $146.50 \pm 35.24$ & $170.75 \pm 21.93$ \\
\hline N2 & $209.67 \pm 21.13$ & $223.83 \pm 21.23$ & $211.17 \pm 37.55$ & $222.83 \pm 16.87$ & $213.33 \pm 23.36$ & $211.00 \pm 26.35$ \\
\hline
\end{tabular}

Data are presented as mean $\pm S D$ of the measured latencies in $m s$ (mouth breathing; $n=6$ ). P1, N1, P2, N2: peak latencies of the first positive, first negative, second positive and second negative components of the respiratory-related evoked potentials, respectively.

airway pressure changes when most of the upper airway (with the exception of the lower part of the larynx) was bypassed through the use of a laryngeal mask. All in all, the current authors feel that it is reasonable to base the following discussion on the fact that the upper airway contributes importantly to the respiratory-related evoked potentials, but are aware that other mechanisms may be involved.

\section{Nose breathing and effects of L-menthol}

It is worth nothing that the present authors did not observe significant differences between the mid-inspiratory occlusion potentials evoked during mouth breathing and during nose breathing, under baseline conditions as well as during anaesthesia. This suggests that this type of potential can be studied interchangeably during one or the other breathing route. This novel information is potentially important for future studies, as nose breathing is the normal breathing route in resting humans.

The inhalation of L-menthol did not affect the respiratoryrelated evoked potentials in the six subjects in which this was studied (tables 3 and 4). Insofar as "cold-receptors" are in fact flow receptors, this is not unexpected with an inspiratory occlusion paradigm. The strong activation of the receptors by

\begin{tabular}{|c|c|c|c|c|c|c|}
\hline \multirow[t]{3}{*}{ TAE } & 3LE 4 & \multicolumn{5}{|c|}{$\begin{array}{l}\text { Amplitudes of the components of the respiratory- } \\
\text { related evoked potentials (measured from } \\
\text { baseline to peak) before, during and after the } \\
\text { inhalation of L-menthol in } \mathrm{Cz}-\mathrm{C} 3 \text { and } \mathrm{Cz}-\mathrm{C} 4\end{array}$} \\
\hline & \multicolumn{3}{|c|}{$\mathrm{Cz}-\mathrm{C}_{3}$} & \multicolumn{3}{|c|}{$\mathrm{Cz}-\mathrm{C}_{4}$} \\
\hline & Before & During & After & Before & During & After \\
\hline P1 & $1.36 \pm 0.43$ & B $1.28 \pm 0.63$ & $1.72 \pm 0.52$ & $1.64 \pm 0.38$ & $1.40 \pm 0.68$ & $1.32 \pm 0.59$ \\
\hline N1 & $2.93 \pm 1.25$ & $2.84 \pm 0.55$ & $3.00 \pm 0.58$ & $3.30 \pm 1.83$ & $3.10 \pm 1.83$ & $3.60 \pm 1.34$ \\
\hline P2 & $0.67 \pm 0.44$ & $0.58 \pm 0.58$ & $0.54 \pm 0.49$ & $0.95 \pm 0.77$ & $0.85 \pm 0.69$ & $0.83 \pm 0.57$ \\
\hline N2 & $2.97 \pm 1.65$ & $2.47 \pm 1.67$ & $2.50 \pm 1.31$ & $3.03 \pm 1.87$ & $3.30 \pm 2.29$ & $3.33 \pm 1.94$ \\
\hline
\end{tabular}

L-menthol could also have led to a saturation of their sensory pathways. Finally, the size of this subgroup may have been insufficient to detect a difference.

\section{Upper airway receptors and topical anaesthesia}

The respiratory sensory innervation of the upper airway is most complex [14, 15, 19, 20] with major interspecies differences. Nasal afferent end-organs comprise many free nerve endings in the nasal epithelium and underneath it [15]. Their activity is markedly affected by topical anaesthesia [21]. Nasal pressure sensitive receptors exist in several species. Their activity is also easily attenuated by topical anaesthesia [19]. Pharyngeal respiratory receptors are scant, and the pharynx is not considered an important reflexogenic site for patency-maintaining reflexes [22]. However, the muscles of the pharyngeal wall contain receptors characteristic of skeletal muscles, as do the muscles of the palate and of the tongue [15]. The laryngeal region is densely innervated. It features flow receptors, abundant transmural pressure receptors and "drive" receptors stimulated by the contraction of intrinsic laryngeal muscle or of the passive motion of the larynx transmitted through the trachea or both $[15,23]$. The first two categories are sensitive to topical anaesthesia [15, 24], whereas this is only partially the case for the "drive receptors" [23, 25] that require both muscle paralysis and tracheal immobilisation to be silenced. These receptors are likely to include ligament receptors, joint receptors and muscle receptors, very abundant in pharyngeal and laryngeal muscles. The afferent activity in response to the stretching of laryngeal muscular receptors is known to persist after topical anaesthesia [26].

\section{Interpretation of results}

In addition to the issues raised in the earlier "preliminary considerations" section, the failure of the anaesthetic to reach all the relevant receptors could be called on to explain the presented result. Indeed, although it is highly likely that nasal and pharyngeal receptors were correctly anesthetised, the current authors did not perform a visually controlled application of lidocaine on the lower part of the larynx. However, partial laryngeal anaesthesia is likely due to the swallowing difficulties noted by all the subjects and by the abolition of the L-menthol induced cold sensation that was consistently noted after anaesthesia during mouth breathing. Insofar as preventing part of the airway receptors from being exposed to a given 
stimulus does significantly alter the corresponding potentials [12], even incomplete anaesthesia would be expected to have some effects on the respiratory-related evoked potentials. From this, the present authors submit that the complete absence of effect of topical lidocaine on the respiratory-related evoked potentials in the presented subjects indicates that the receptors activated by the inspiratory occlusions are not sensitive to topical anaesthesia (of note, it has been shown that upper airway receptors that are sensitive to topical anaesthesia are not essential for respiratory sensations related to volume changes [27]). Speculatively, this suggests that the upper airway receptors relevant to the respiratory-related evoked potentials could belong to the "drive receptors" described earlier (joint and muscular upper airway receptors). Although they would probably be very difficult to conduct in humans, studies specifically designed to test this hypothesis are warranted.

According to the earlier discussion, this makes a contribution of cold receptors and of pressure receptors unlikely (which is not surprising regarding cold receptors considering that the stimulus generated by mid-inspiratory occlusion occurs in the absence of flow; in this frame, modifying the baseline activity of the laryngeal flow receptors by the inhalation of L-menthol did not induce visible changes in the characteristics of the respiratory-related evoked potentials). In conclusion, the authors submit that the upper airway receptors involved in the respiratory-related evoked potentials following midinspiratory occlusions could mainly belong to the category of the "drive receptors". If this was correct, joint and muscular airway receptors would appear to be important determinants of the detection and processing of the mechanical changes induced by this type of stimulus by the cerebral cortex, phenomena that are paramount to the control of upper airway patency.

\section{REFERENCES}

1 Gandevia SC, Macefield G. Projection of low-threshold afferents from human intercostal muscles to the cerebral cortex. Respir Physiol 1989; 77: 203-214.

2 Straus C, Zelter M, Derenne J-P, Pidoux B, Willer J, Similowski T. Putative projection of phrenic afferents to the limbic cortex in man studied with cerebral evoked potentials. J Appl Physiol 1997; 82: 480-490.

3 Zifko UA, Young BG, Remtulla H, Bolton CF. Somatosensory evoked potentials of the phrenic nerve. Muscle Nerve 1995; 18: 1487-1489.

4 Davenport PW, Friedman WA, Thompson FJ, Franzen O. Respiratory-related cortical potentials evoked by inspiratory occlusion in humans. J Appl Physiol 1986; 60: 1843-1848.

5 Revelette WR, Davenport PW. Effects of timing of inspiratory occlusion on cerebral evoked potentials in humans. J Appl Physiol 1990; 68: 282-288.

6 Hammond CS, Gaeta H, Sapienza C, Davenport PW. Respiratory-related evoked potential elicited by expiratory occlusion. J Appl Physiol 1999; 87: 835-842.

7 Knafelc M, Davenport PW. Relationship between resistive loads and P1 peak of respiratory-related evoked potential. J Appl Physiol 1997; 83: 918-926.
8 Strobel RJ, Daubenspeck JA. Early and late respiratoryrelated cortical potentials evoked by pressure pulse stimuli in humans. J Appl Physiol 1993; 74: 1484-1491.

9 Grippo A, Carrai R, Romagnoli I, Pinto F, Sanna A. Respiratory-related evoked potential and upper airway transmural pressure change by using the negative expiratory pressure (NEP) device. Clin Neurophysiol 2003; 114: 636.

10 Knafelc M, Davenport PW. Relationship between magnitude estimation of resistive loads, inspiratory pressures, and the RREP P(1) peak. J Appl Physiol 1999; 87: 516-522.

11 Davenport PW, Cruz M, Stecenko AA, Kifle Y. Respiratory-related evoked potentials in children with life-threatening asthma. Am J Respir Crit Care Med 2000; 161: 1830-1835.

12 Daubenspeck JA, Manning HL, Akay M. Contribution of supraglottal mechanoreceptor afferents to respiratoryrelated evoked potentials in humans. J Appl Physiol 2000; 88: 291-299.

13 Donzel-Raynaud C, Straus C, Bezzi M, et al. Upper airway afferents are sufficient to evoke the early components of respiratory-related cortical potentials in humans. J Appl Physiol 2004; 97: 1874-1879.

14 Sant'Ambrogio G, Tsubone H, Sant'Ambrogio FB. Sensory information from the upper airway: role in the control of breathing. Respir Physiol 1995; 102: 1-16.

15 Widdicombe J, Sant'Ambrogio G, Mathew OP. Nerve receptors of the upper airway. In: Mathew OP, Sant'Ambrogio FB, eds. Respiratory function of the airway. New York, Marcel Dekker, 1988; pp. 193-232.

16 Bezzi M, Donzel-Raynaud C, Straus C, et al. Unaltered respiratory-related evoked potentials after acute diaphragm dysfunction in humans. Eur Respir J 2003; 22: 625-630.

17 Davenport PW, Holt GA, Hill PM. The effect of increased inspiratory drive on the sensory activation of the cerebral cortex by inspiratory occlusion. In: Speck DF, Dekin MS, Revelette WR, Frazier DT, eds. Respiratory control: central and peripheral mechanisms. Lexington, USA, University Press of Kentucky, 1992; pp. 216-221.

18 Nishino T, Tagaito Y, Sakurai Y. Nasal inhalation of Lmenthol reduces respiratory discomfort associated with loaded breathing. Am J Respir Crit Care Med 1997; 156: 309-313.

19 Widdicombe J. Nasal and pharyngeal reflexes. In: Mathew OP, Sant'Ambrogio G, eds. Respiratory function of the airway. New York, Marcel Dekker, 1988; pp. 233-258.

20 Mathew OP, Sant'Ambrogio FB. Laryngeal reflexes. In: Mathew OP, Sant'Ambrogio G, eds. Respiratory function of the airway. New York, Marcel Dekker, 1988; pp. 259-302.

21 Orani GP, Anderson JW, Sant'Ambrogio G, Sant'Ambrogio FB. Upper airway cooling and 1-menthol reduce ventilation in the guinea pig. J Appl Physiol 1991; 70: 2080-2086.

22 Horner RL, Innes JA, Holden HB, Guz A. Afferent pathway(s) for pharyngeal dilator reflex to negative pressure in man: a study using upper airway anaesthesia. J Physiol 1991; 436: 31-44.

23 Sant'Ambrogio G, Mathew OP, Sant'Ambrogio FB. Role of intrinsic muscles and tracheal motion in modulating laryngeal receptors. Respir Physiol 1985; 61: 289-300. 
24 Mathew OP, Abu-Osba YK, Thach BT. Genioglossus muscle responses to upper airway pressure changes: afferent pathways. J Appl Physiol 1982; 52: 445-450.

25 Kuna ST, Woodson GE, Sant'Ambrogio G. Effect of laryngeal anesthesia on pulmonary function testing in normal subjects. Am Rev Respir Dis 1988; 137: 656-661.
26 Abo-El-Eneim M, Wyke B. Laryngeal myotatic reflexes. Nature 1966; 209: 682-686.

27 DiMarco AF, Wolfson DA, Gottfried SB, Altose MD. Sensation of inspired volume in normal subjects and quadriplegic patients. J Appl Physiol 1982; 53: 1481-1486. 